\title{
Bentonite replacing part of cement concrete for resistance to chloride ion attack
}

\author{
Jie Luo ${ }^{1}$, Chuanchang $\mathrm{Li}^{2}$, Yafei $\mathrm{Ma}^{1}$ and Lei Wang ${ }^{1, *}$ \\ ${ }^{1}$ School of Civil Engineering, Changsha University of Science and Technology, Changsha, Hunan, 410114, China \\ ${ }^{2}$ School of Energy and Power, Changsha University of Science and Technology, Changsha, Hunan, 410114, China
}

\begin{abstract}
Bentonite is known as a kind of natural pozzolan that can improve the mechanical properties of cementitious materials and reduce the overall $\mathrm{CO}_{2}$ output of cement production. This study is designed to evaluate the feasibility of using bentonite as a substitute for cement in concrete and analyze the effect of bentonite on resisting chloride ion penetration. The concrete was replaced by equal-quality bentonite for $0 \%$, $5 \%, 10 \%, 15 \%$ and $20 \%$ cement respectively, and the water-cement ratio, fine and coarse aggregate content remained constant. The results indicated that as the bentonite content increased, the compressive strength of the mixes increased first and then decreased. The sample containing $10 \%$ bentonite got a higher compressive strength than the other samples. The rapid chloride migration (RCM) tests showed that the samples containing bentonite had better resistance to chloride ion attack than samples without bentonite against chloride, especially the sample containing $10 \%$ bentonite. It can be concluded that the concrete with $10 \%$ bentonite can improve the resistance to chloride ion diffusion with high compressive strength.
\end{abstract}

\section{Introduction}

Since the discovery of Ordinary Portland cement, it has been the most commonly used binder in concrete. While in the current construction industry, the production of cement is an important factor in the production of greenhouse gases. It shows that nearly $7 \%$ of the world's total $\mathrm{CO}_{2}$ production comes from cement production process, and this trend is expected to remain stable over the next decade. [1, 2]. In order to reduce energy consumption, achieve sustainable resources, environmental protection and improve the durability of building structures, there is an urgent need to find lowcost natural pozzolans to replace the cement[3-6].

Natural pozzolans have many properties, such as high ultimate strength, low heat of hydration, low permeability, and high sulfate resistance, which make it a great benefit in mortar and concrete.[7, 8]. Bentonite, a natural pozzolan, is composed primarily of montmorillonite. The crystal structure of montmorillonite is a 2:1 type layered silicate. Each unit cell consists of a layer of aluminum oxide octahedron sandwiched between two layers of silicon oxide tetrahedra. Bentonite is classified into sodium bentonite and calcium bentonite by attributes [911]. According to the study of many scholars, the use of sodium bentonite instead of cement is much better than calcium bentonite. The bentonite in China is very rich and it is more available than other pozzolans. Bentonite will help reduce greenhouse gas emissions and it will have a positive effect on system durability $[12,13]$.
Some research has been conducted to study the effect of bentonite on the properties of mortar and concrete. Results from these previous studies indicated that bentonite can improve the pore structure of cementitious materials, thereby improving the durability of the structure, and the compressive strength of the concrete decreased as the bentonite content increased [8, 14]. Additionally, the ability of mortar with bentonite to resist sulfuric acid attack has been also investigated $[2,15]$. Mirza J. found that in the amount of bentonite should be controlled below $25 \%$ to ensure the strength of concrete [8]. The optimum dosage needs to be determined by experiments. And the resistance of concrete containing bentonite to hydrochloride acid attack needs to be explored.

The purpose of this study was to evaluate the feasibility of replacing partial cement with bentonite, and to analyze the influence of the two factors of bentonite content and water-cement ratio on concrete. The resistance of concrete containing bentonite to hydrochloride acid attack is investigated. This study is arranged as follows. First, material parameters, specimens preparation, and methodology are introduced. Next, experimental results are presented and discussed. Finally, several conclusions derived from the study are obtained. 


\section{Experimental}

\subsection{Materials}

Sodium bentonite produced in Nanjing was used as partial substitute of cement. The sample was sieved through mesh 200 sieve.
The ordinary Portland cement used was produced by Xinxing Cement Factory in Changsha. The chemical composition of bentonite and cement are shown in table 1 .

The fine aggregate used for concrete was natural river sand mined from Changsha with a fineness modulus of 2.3. The coarse aggregate used for concrete was natural limestone from Changsha with a bulk specific gravity 2.68 , and the maximum size of the coarse aggregate is $20 \mathrm{~mm}$.

Table 1. Chemical composition of the cementitious materials.

\begin{tabular}{ccc}
\hline & \multicolumn{2}{c}{ Chemical composition $(\%)$} \\
\cline { 2 - 3 } & $($ Cement $)$ & (Bentonite) \\
\cline { 2 - 3 } Silicon dioxide $\left(\mathrm{SiO}_{2}\right)$ & 21.65 & 70.12 \\
Magnesium oxide $(\mathrm{MgO})$ & 2.12 & 3.16 \\
Aluminum oxide $\left(\mathrm{Al}_{2} \mathrm{O}_{3}\right)$ & 7.51 & 12.19 \\
Calcium Oxide $(\mathrm{CaO})$ & 61.8 & 3.52 \\
Ferric oxide $\left(\mathrm{Fe}_{2} \mathrm{O}_{3}\right)$ & 3.96 & 5.12 \\
Phosphorus pentoxide $\left(\mathrm{P}_{2} \mathrm{O}_{5}\right)$ & 0.04 & 0.11 \\
Sodium oxide $\left(\mathrm{Na}_{2} \mathrm{O}\right)$ & 0.37 & 5.06 \\
Potassium oxide $\left(\mathrm{K}_{2} \mathrm{O}\right)$ & 0.82 & 0.56 \\
Titanium oxide $\left(\mathrm{TiO}_{2}\right)$ & & 0.15 \\
Manganese oxide $(\mathrm{MnO})$ & & 0.07 \\
\hline
\end{tabular}

\subsection{Specimen preparation}

This research prepared five different mixes with two different water-cement ratio $(\mathrm{W} / \mathrm{C})$ respectively. The five mixes include a control mix without the addition of bentonite, and the other four mixes that replaced the cement in the concrete with different proportions of bentonite. The five mixes are shown in table 2 .

This research prepared concrete cubes with a size of $100 \mathrm{~mm} \times 100 \mathrm{~mm} \times 100 \mathrm{~mm}$ at a constant $\mathrm{W} / \mathrm{C}$ of 0.55 and 0.36 . Four mixes replaced $5 \%, 10 \%, 15 \%$ and $20 \%$ of the cement in the concrete with an equal mass of bentonite respectively, and one control mix without adding bentonite. The concrete cubes were tested for the compressive strength test after 7, 14, 28 days of curing.

This research prepared concrete cylinders with a size of $100 \mathrm{~mm} \times 50 \mathrm{~mm}$ at a constant $\mathrm{W} / \mathrm{C}$ of 0.55 and 0.36 .
Four mixes replaced $5 \%, 10 \%, 15 \%$ and $20 \%$ of the cement in the concrete with an equal mass of bentonite respectively, and one control mix without adding bentonite. The concrete cylinders were used to the hydrochloride acid attack test after 28 days of curing.

All the concrete specimens were kept in a curing cabinet and cured at a laboratory ambient temperature of $21 \pm 1^{\circ} \mathrm{C}$ and $95 \%$ relative humidity until testing.

The mixes were abbreviated in one way, LXBX. In LXBX, the LX represents the batch with a specific watercement ratio, $\mathrm{L} 1$ represents the batch with $\mathrm{W} / \mathrm{C}$ of 0.36 , and L2 represents the batch with $\mathrm{W} / \mathrm{C}$ of 0.55 . BX indicates the amount of cement that has been replaced by bentonite. For example, the specific designation, L1B5, is expressed as the sample in which bentonite replaces 5\% of cement when the water-cement ratio is 0.55 .

Table 2. Mix design.

\begin{tabular}{cccccccc}
\hline Mix & W/C & Cement $\left(\mathrm{kg} / \mathrm{m}^{3}\right)$ & Bentonite $\left(\mathrm{kg} / \mathrm{m}^{3}\right)$ & $\begin{array}{c}\text { Fine } \\
\text { aggregate }\left(\mathrm{kg} / \mathrm{m}^{3}\right)\end{array}$ & $\begin{array}{c}\text { Coarse } \\
\text { aggregate }(\mathrm{kg} / \mathrm{m} \\
\left.{ }^{3}\right)\end{array}$ & Water $\left(\mathrm{kg} / \mathrm{m}^{3}\right)$ & $\begin{array}{c}\text { Superplasticize } \\
\mathrm{r}\left(\mathrm{kg} / \mathrm{m}^{3}\right)\end{array}$ \\
\hline L1B0 & 0.36 & 372 & 0 & 446 & 781 & 134 & 11.15 \\
L1B5 & 0.36 & 375 & 20 & 395 & 790 & 142 & 15.8 \\
L1B10 & 0.36 & 356 & 40 & 395 & 790 & 142 & 15.8 \\
L1B15 & 0.36 & 335 & 59 & 394 & 789 & 142 & 17.7 \\
L1B20 & 0.36 & 315 & 79 & 394 & 787 & 142 & 19.7 \\
L2B0 & 0.55 & 340 & 0 & 829 & 1009 & 198 & 0
\end{tabular}




\begin{tabular}{cccccccc} 
L2B5 & 0.55 & 323 & 17 & 829 & 1009 & 198 & 0 \\
L2B10 & 0.55 & 300 & 34 & 829 & 1009 & 198 & 0 \\
L2B15 & 0.55 & 289 & 51 & 829 & 1009 & 198 & 0 \\
L2B20 & 0.55 & 272 & 68 & 829 & 1009 & 198 & 0 \\
\hline
\end{tabular}

\subsection{Methodology}

The compressive strength test of concrete cube is measured by the universal testing machine, while the

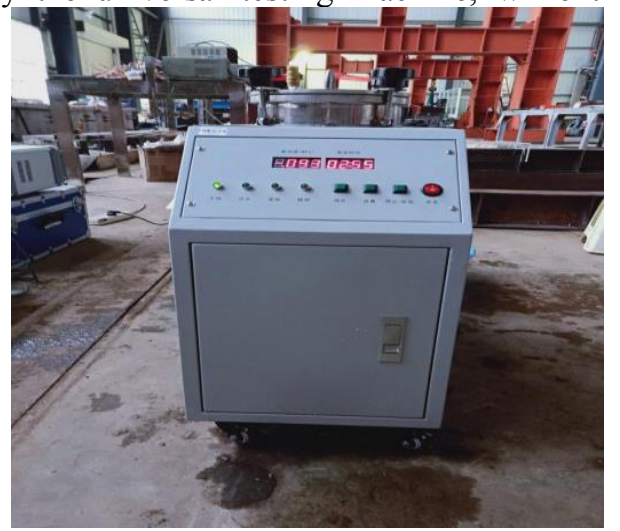

Figure 1. Intelligent vacuum water tank. chloride resistance of the concrete cylinder is determined by $\mathrm{RCM}$ (Rapid Chloride Migration) chloride ion diffusion coefficient tester as shown in figure 1 and figure 2. The hydrates of the samples was studied by scanning electron microscope.

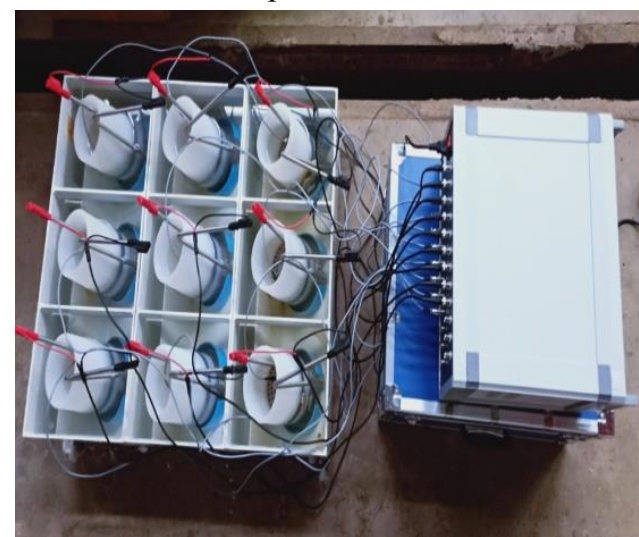

Figure 2. RCM concrete chloride ion diffusion coefficient analyser.

The results of the compressive strength of the five mixes with two different water-cement ratio at different days are graphically shown in figure 3 and figure 4 .

\section{Result and discussion}

\subsection{Compressive strength}

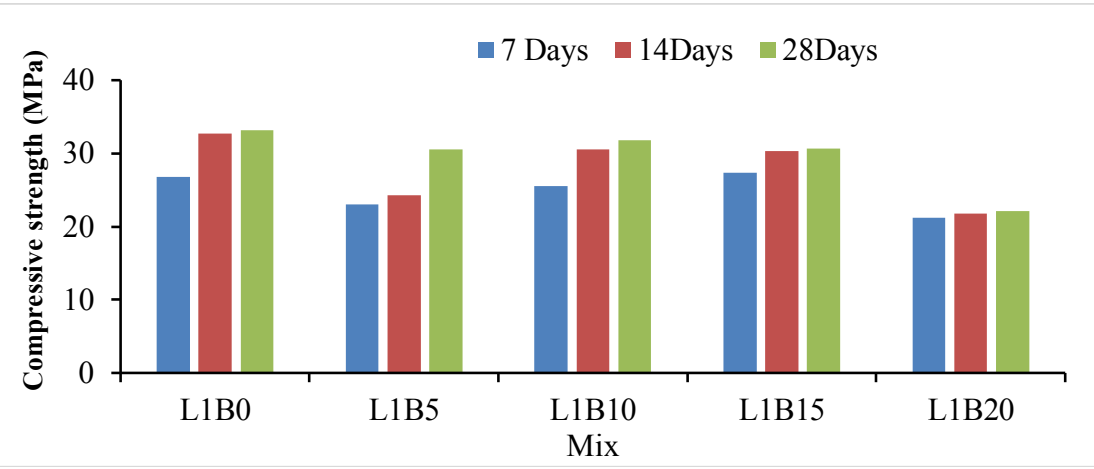

Figure 3. Compressive strength of the mixes when $\mathrm{W} / \mathrm{C}$ is 0.36 at different ages. 


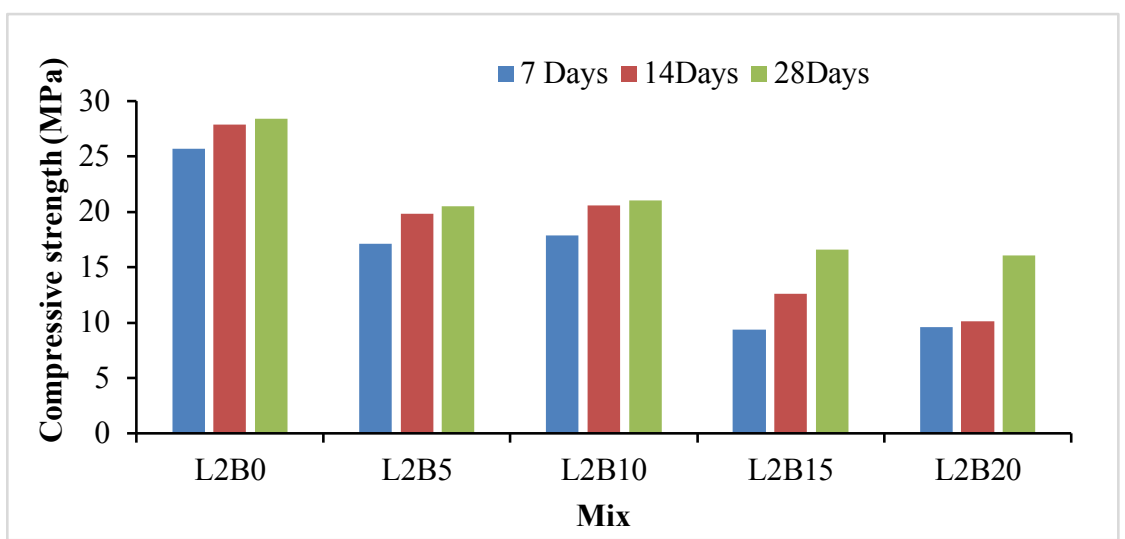

Figure 4. Compressive strength of the mixes when $\mathrm{W} / \mathrm{C}$ is 0.55 at different ages.

From the results of Figure 3 and Figure 4, it can be concluded that:

As the curing period increased, the compressive strength of all the mixes increased from 7 to 28 days.

At 28 days, for the low $\mathrm{W} / \mathrm{C}$ specimens $(\mathrm{W} / \mathrm{C}=0.36)$, the mixes containing bentonite (L1B5, L1B10, L1B15, L1B20) showed $8.1 \%, 4.2 \%, 7.8 \%$ and $33.4 \%$ lower strength than $\mathrm{L} 1 \mathrm{~B} 0$, and for the high $\mathrm{W} / \mathrm{C}$ specimens $(\mathrm{W} / \mathrm{C}=0.55)$, the mixes containing bentonite (L2B5, L2B10, L2B15, L2B20) showed 27.8\%, 26.0\%, 41.5\% and $43.3 \%$ lower strength than L2B0. The mixes with a low $\mathrm{W} / \mathrm{C}$ had higher compressive strength than those with a high $\mathrm{W} / \mathrm{C}$ under different substitutions of bentonite. This indicates that the high bentonite content and high watercement ratio have a negative impact on the performance of concrete.

For the two kinds of $\mathrm{W} / \mathrm{C}$, they have the same tendency that the compressive strength increased first and then decreased as the bentonite content of the cement substitute increased. According to the results of the compressive strength of the mixes, it showed that the mix containing $10 \%$ bentonite replacement of cement (L1B10 and L2B10) can achieve a considerable strength compared with the

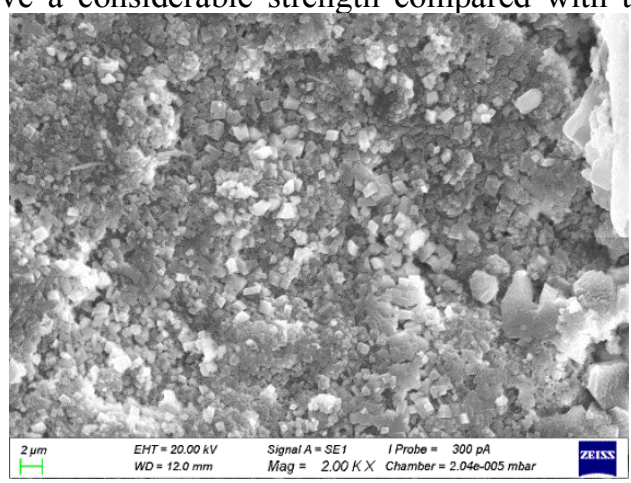

(a) others. Therefore, according to the tendency of the compressive strength development, there may exist an unexplored mix that has a higher compressive strength than the mix containing $10 \%$ bentonite between $5 \%$ to $15 \%$ bentonite. This needs further research.

\subsection{Scanning electron microscopy}

The microphotographs of parts of hardened L1B0, L1B5, L1B10, L1B15 and L1B20 samples obtained by scanning electron microscope are shown in figure.3(a-e). And the L2B20 is shown in figure 5(f) as a representative of high $\mathrm{W} / \mathrm{C}$ of 0.55 to compare with the results of figure 5(a-e).

The scanning electron microscope can provide a close insight into the microstructure of the hydrates. The figure 5(a) is the sample L1B0 without bentonite, it can be seen that the cement clinker hydration reaction is relatively complete, calcium silicate hydrates(C-S-H) is interwoven with calcium hydroxide $(\mathrm{CH})$, and a small amount of acicular ettringite (Aft) can be seen. The hydration results of L1B5 showed in figure5(b) are very similar to figure $5(\mathrm{a})$, while the surface of the hydration product

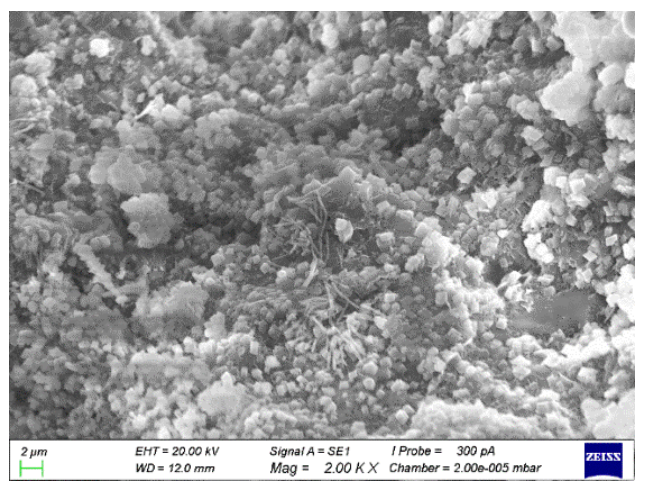

(b) 


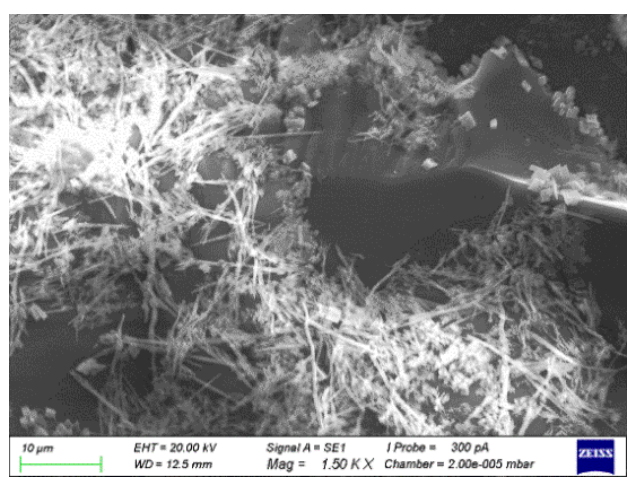

(c)

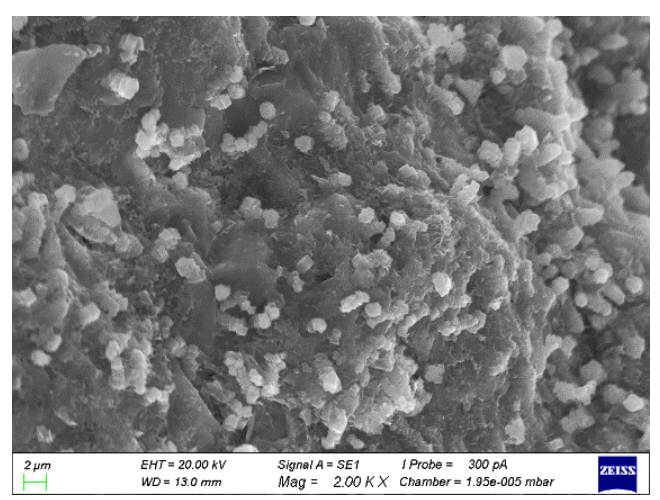

(e)

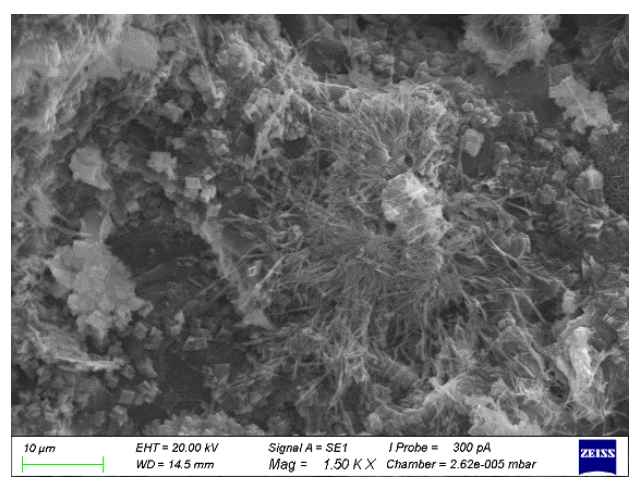

(d)

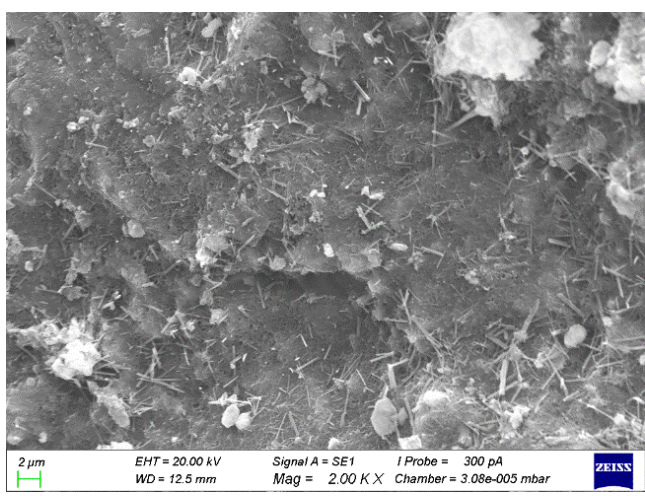

(f)

Figure 5. SEM graphs of 28days hydration:(a)L1B0; (b)L1B5; (c)L1B10; (d)L1B15; (e)L1B20; (f)L2B20.

in figure 5(b) is denser, the hydration product AFt is more obvious. A large amount of AFt appeared and the hydration product $\mathrm{CH}$ significantly reduced in figure 5(c) compared with figure 5(a) and figure 5(b), the surface is smooth and no pores are been seen. In figure 5(d), C-S$\mathrm{H}$ is interlaced with $\mathrm{CH}$, with a certain amount of $\mathrm{AFt}$ interspersed in the middle. L1B20 containing the largest amount of bentonite has a lot of $\mathrm{CH}$ and $\mathrm{C}-\mathrm{S}-\mathrm{H}$, the surface is rather rough in figure 5(e). Figure 5(f) is different from the figure $5(\mathrm{a}-\mathrm{e})$ due to the $\mathrm{W} / \mathrm{C}$ is 0.55 , the hydration results of L2B20 shows a loose structure with

$$
D_{\mathrm{RCM}}=\frac{0.0239 \times(273+T) L}{(U-2) t}\left(X_{d}-0.0238 \sqrt{\frac{(273+T) L X_{d}}{U-2}}\right)
$$

Where $U$ is the absolute value of the voltage used, $T$ is the average of the initial and final temperatures of the anode solution, $L$ is the thickness of the specimen, $X_{d}$ is obvious small pores and a small amount of $\mathrm{AFt}$ and $\mathrm{CH}$ compared with figure 5(e).

\subsection{Acid attack resistance}

As prescribed in the standard for test method of long-term performance and durability of ordinary concrete (GB-T 50082-2009). the chloride ion diffusion coefficient of $\mathrm{RCM}$ method is defined as:

the average value of the penetration depth of chloride ion, and $t$ is the time that the test lasted.

Table 3. The value chloride diffusion coefficient.

\begin{tabular}{cccccc}
\hline $\mathrm{D}_{\mathrm{RCM}}$ & $\mathrm{B} 0$ & $\mathrm{~B} 5$ & $\mathrm{~B} 10$ & $\mathrm{~B} 15$ & $\mathrm{~B} 20$ \\
\hline $\mathrm{W} / \mathrm{C}=0.36$ & 6.236 & 4.777 & 2.625 & 5.226 & 4.01 \\
$\mathrm{~W} / \mathrm{C}=0.55$ & 10.073 & 7.465 & 6.194 & 8.317 & 9.6 \\
\hline
\end{tabular}

The results of the RCM method for testing the chloride ion diffusion coefficient are shown in table 3 and figure 6 . The results indicated that:

When $\mathrm{W} / \mathrm{C}$ is 0.55 , the chloride ion diffusion coefficient of bentonite-concrete shows a trend of decreasing first and then increasing with the increase of bentonite content. when $\mathrm{W} / \mathrm{C}$ is 0.55 , it has a similar trend before the bentonite replaces $15 \%$ of the cement. Compared to the mixes with low $\mathrm{W} / \mathrm{C}$, the difference is that the L2B20 is lower than L2B15. 
In the case of different water-cement ratios, when the bentonite replaces $10 \%$ of the cement in mass, the chloride ion diffusion coefficient gets the lowest value.

The chloride ion diffusion coefficient increased as the $\mathrm{W} / \mathrm{C}$ increased. The penetration of chloride ions into concrete is mainly through the connected pores and microcracks in the concrete. After the hydration reaction, the hole where the original water is located forms a hole. The larger the water-cement ratio, the more pores are formed, and the easier it is to form connected pores, thereby increasing the propagation path of chloride ions in concrete and reducing the chloride ion permeability of bentonite-concrete.

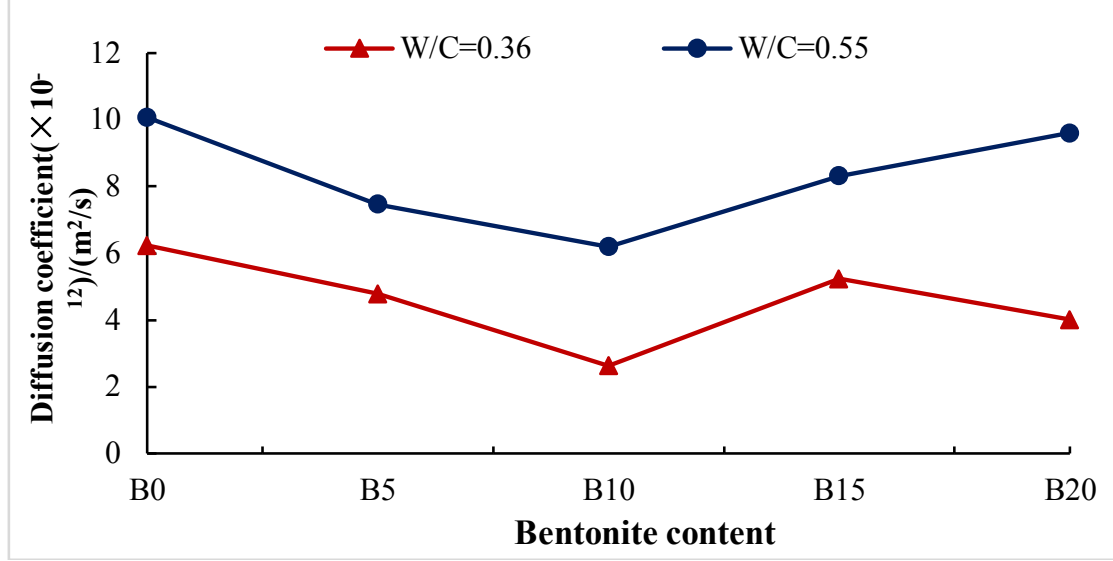

Figure 6. Relationship between chloride ion diffusion coefficient and bentonite content of concrete containing bentonite.

\section{Conclusions and recommendations}

Based on the finding of the experimental results, the main conclusions of this research are as follows:

- $\quad$ As the curing period increased from 7 to 28 days, the compressive strength of the mix increased. The control mix without bentonite have higher compressive strength than the mixes that contain bentonite.

- In the case of a certain water-cement ratio, the compressive strength increased first and then decreased with the bentonite content increased. When the bentonite replaces $10 \%$ cement in mass, the mix got a higher compressive strength than the other mixes containing bentonite, and it shows $4.2 \%$ lower strength than the control mix when the $\mathrm{W} / \mathrm{C}$ is 0.36 .

- The hydration results of the mix with high watercement material ratio have a poor structure and more pores compared with these with low water-cement ratio.

- The RCM test demonstrated that mixes with bentonite was better than the control mix in resisting chloride ion attack. The mixes with low $\mathrm{W} / \mathrm{C}$ have a stronger resistance to chloride attack compared with high $\mathrm{W} / \mathrm{C}$ specimens. The value of the chloride ion diffusion coefficient of the mixes containing $10 \%$ bentonite is $42 \%$ of the control mix. This indicates that the diffusion rate of chloride ions is slowed by half.

- According to the tendency of compressive strength development, some further research is needed to find out the optimum amount of bentonite to replace cement between $5 \%$ and $15 \%$.

\section{References}

1. Shi, C., Jiménez, A.F., and Palomo, A. (2011) New cements for the 21 st century: The pursuit of an alternative to Portland cement. Cement and Concrete Research, 41(7): 750-763.

2. Memon, S.A., et al. (2012) Utilization of Pakistani bentonite as partial replacement of cement in concrete. Construction and Building Materials, 30: 237-242.

3. Taylor-Lange, S.C., Juenger, M.C.G. and Siegel, J.A. (2013) Impact of cement renders on airborne ozone and carbon dioxide concentrations. Atmospheric Environment, 70: 263-266.

4. Tironi, A., et al. (2012) Kaolinitic calcined clays: Factors affecting its performance as pozzolans. Construction and Building Materials, 28(1): 276-281.

5. Peng, M.X., et al. (2017) Alkali fusion of bentonite to synthesize one-part geopolymeric cements cured at elevated temperature by comparison with two-part ones. Construction and Building Materials, 130: 103112.

6. Sha, F., et al. (2018) Experimental study on performance of cement-based grouts admixed with fly ash, bentonite, superplasticizer and water glass. Construction and Building Materials, 161: 282-291.

7. A.C.I. (1994) Use of Natural Pozzolans in Concrete (ACI 232.1R). ACI Materials Journal, 91(4): 410-26.

8. Mirza, J., et al. (2009). Pakistani bentonite in mortars and concrete as low cost construction material. Applied Clay Science, 45(4): 220-226.

9. Paluszkiewicz, C., Holtzer, M., Bobrowski, A. (2008) FTIR analysis of bentonite in moulding sands. Journal of Molecular Structure, 880(1): 109-114. 
10. Xu, C., Huang, L., Xing, H.F. (2010) Influence of cement-bentonite slurry mixing ratio on permeability of cutoff wall. Rock \& Soil Mechanics, 31(2): 442426.

11. Terzić, A., et al. (2018) The effect of alternations in mineral additives (zeolite, bentonite, fly ash) on physico-chemical behavior of Portland cement based binders. Construction and Building Materials, 180: 199-210.

12. Rodríguez-Camacho, R.E., Uribe-Afif, R. (2002) Importance of using the natural pozzolans on concrete durability. Cement \& Concrete Research, 32(12): 1851-1858.

13. Isaia, G.C., Gastaldini, A.L.G., Moraes, R. (2003) Physical and pozzolanic action of mineral additions on the mechanical strength of high-performance concrete. Cement and Concrete Composites, 25(1): 69-76.

14. Ahmad, S.B., S.A. Elahi, A. (2011) Effect of Pakistani bentonite on properties of mortar and concrete. Clay Minerals, 46(1): 85-92.

15. Babaki, H., Salem, A., Jafarizad, A. (2008) Kinetic model for the isothermal activation of bentonite by sulfuric acid. Materials Chemistry and Physics, 108(2): 263-268. 